\title{
The effects of ECS on ECT: Implications for behavioral research*
}

\author{
JAMES R. MISANIN ${ }^{\dagger}$ \\ Susquehanna University, Selinsgrove, $\mathrm{Pa} .17870$
}

Two experiments were performed to determine the temporal pattern of ECS-induced changes in the electroconvulsive threshold (ECT) of the rat. The results indicate that immediately and for a short period of time after receiving a single ECS, the ECT of the rat is elevated, whereas $24 \mathrm{~h}$ after ECS, the rat's ECT is depressed. Some implications of these findings for research on the behavioral effects of ECS are discussed.

In determining the electroconvulsive threshold (ECT) of animals, a procedure typically used requires repeated electrical stimulation of each animal, the stimulus intensity being increased gradually from subconvulsive levels to the minimal level at which the animal convulses (Essig, Groce, \& Williamson, 1961; Golub \& Morgan, 1945; Meritt \& Putnam, 1938). Some investigators using this procedure have reported a marked elevation in ECT when successive threshold estimates were obtained at short intervals (e.g., Essig, Groce \& Williamson, 1961), whereas others (e.g., Meritt \& Putnam, 1938) have pointed out that threshold estimates are constant when obtained on successive days. The apparent constancy of daily threshold estimates may, however, be simply an artifact of the repeated-stimulation procedure. Golub \& Morgan (1945) reported that the successive subliminal stimulations are, in themselves, sufficient to elevate the ECT of the rat, and Woodbury \& Davenport (1952) reported that for rats of any given age ECTs tend to be lower if the induction of seizures was begun early in life, suggesting a possible facilitory effect of convulsive episodes on subsequent ones. Thus, it is possible that electroconvulsive shock (ECS) produces a lower ECT at an ECS-ECT interval of $24 \mathrm{~h}$, but that repeated subliminal stimulations used in determining the ECT elevates it to some consistent level so that there is an apparent constancy from day to day.

The present study sought to determine the temporal pattern of change in ECT produced by a single ECS using a threshold determining procedure that does not require repeated subliminal stimulations.

*This research was supported in part by Grants MH-07129 and $11-1562$ from the National Institute of Mental Health: preparation of the manuscript was supported by Grant IIH 17207. The material reported herein is from a thesis submitted by the author to Rutgers Lniversity in partial fulfilment of the requirements for the $\mathrm{PhD}$ degree.

The author wishes to thank Byron A. Campbell and Donald J. Lewis for their support of this research.

\section{EXPERIMENT 1 \\ Subjects}

The Ss were 480250 - to $350 . \mathrm{g}$ female albino rats (discarded breeders) of the Sprague-Dawley strain purchased from Perfection Breeders, Douglassville, Pa. All Ss were group housed and had free access to food and water, except for a $5.5-\mathrm{min}$ period preceding treatment.

\section{Apparatus}

The ECS stimulator was a constant voltage source (cf. Campbell \& Teghtsoonian, 1958).

\section{Procedure}

Initially $380 \mathrm{Ss}$ were given ECS, $300 \mathrm{~V}$ for $.5 \mathrm{sec}$, through dampened alligator clips attached to their ears. The remaining 100 Ss, given pseudo-ECS, served as controls. The $S$ s were divided in to nine groups, seven experimental and two control. One of the experimental groups $(.09 \mathrm{~h})$ contained 70 Ss and one $(384 \mathrm{~h})$ contained $60 \mathrm{Ss}$; the remaining groups contained $50 \mathrm{Ss}$ each. All groups were divided into subgroups of 10 Ss each.

In order to determine the effect of ECS on the ECT of the rat, each experimental group was subjected to a second shock stimulation at one of seven temporal intervals, $.09, .38,1.5,6.0,24,96$, or $384 \mathrm{~h}$, after the initial ECS. Each subgroup of an experimental or control group was subjected to a single shock of a different intensity for $.5 \mathrm{sec}$. Intensity levels were determined on the basis of pilot data and were intended to bracket the level of shock at which $50 \%$ of the Ss of a group convulsed. These values were within the range of $60-110 \mathrm{~V}$ for all groups except the group tested at $.09 \mathrm{~h}$ after the initial ECS. The levels of shock used in determining ECT for this group ranged from 160-260 V in $20 . \mathrm{V}$ steps. One subgroup of this group was subjected to $80 \mathrm{~V}$ for comparative purposes only (see inset, Fig. 1). The criterion for a convulsion was the tonic extension of the hind legs, the most distinguishing feature of a maximal seizure pattern (Woodbury \& Davenport, 1952).

Results

The percentage of animals in each treatment group convulsing at each of the shock levels was converted to a $\mathrm{z}$ score and a best-fitting straight line for each group's scores was determined by the method of least squares. The ECT, that level of shock at which the line intersected the $50 \%$ $(z=0)$ point, was then computed for each treatment group. Figure 1 shows the ECT in volts for Ss at each ECS-ECS interval and for control Ss. The top and bottom lines of the horizontal bar in the figure represent the ECT values obtained for the two control groups. Two control groups were run in order to provide some indication of the variability in ECT estimates for animals not previously given ECS. The obtained difference in the estimates for these two groups is small in comparison with the overall difference obtained between estimates of ECT for the experimental groups. It appears that immediately and a short period of time after the initial ECS, the ECT of the rat is elevated, whereas at an ECS.ECS interval of $24 \mathrm{~h}$, it is slightly depressed. A chi-square analysis on the number of Ss convulsing at $80 \mathrm{~V}$ (inset, Fig. 1) when tested between .09 and $24 \mathrm{~h}$ after the initial ECS suggests that there is a reliable change in threshold over this interval (chi-square $=11.27, \mathrm{df}=4, \mathrm{p}<.005)$. \section{EXPERIMENT 2}

The plan of this experiment was to confirm the findings of Experiment 1 . In that experiment the ECS stimulator was a constant voltage ac source delivering a $60-\mathrm{Hz}$ current for $.5 \mathrm{sec}$. Since a constant voltage $(300 \mathrm{~V})$ was applied to each animal with this source, the current flowing through the rat was a function of the animal's impedance which is primarily

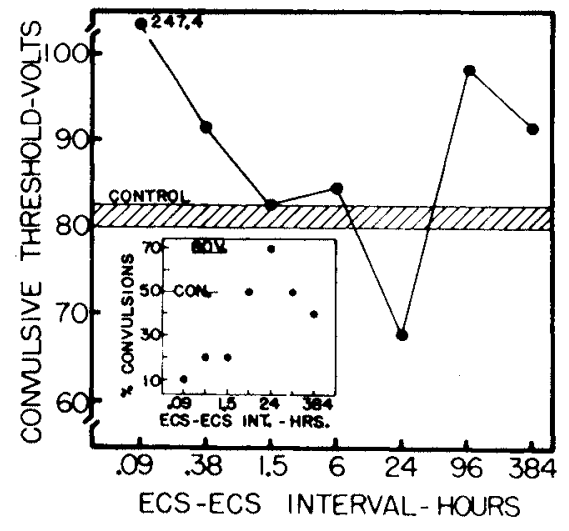

Fig. 1. The convulsive threshold in $V$ as a function of time in h after an initial ECS. The top and bottom lines of the horizontal bar indicate threshold estimates for two control (no initial ECS) groups. The inset shows the percentage of $S s$ in each treatment group convulsing at $80 \mathrm{~V}$. Note that $h$ are on a $\log$ scale. 
resistive (Russell, Pierce, \& Townsend, 1949). As the observed elevated ECT following ECS could result from a change in tissue impedance, it seemed necessary to replicate the major findings of Experiment 1 using a stimulator that delivered a relatively constant current. Because of the ancillary nature of the present experiment, only two ECS-ECS intervals were investigated, those at which the maximum elevation and depression of ECT were obtained in the previous experiment.

\section{Subjects}

The Ss were 120 Sprague-Dawley female albino rats between 250 and $350 \mathrm{~g}$ obtained from Perfection Breeders. Three groups of $40 \mathrm{Ss}$ each were equated on the basis of body weight and given differential treatment during the experiment. The maintenance of Ss was the same as that for Ss of Experiment 1.

\section{Apparatus}

The ECS source was a Beckman Type 735 Liberson brief stimulus therapy apparatus. The shocks delivered were $220 \mathrm{~Hz}$ alternating pulse current with a .5-msec positive component. The shock was applied to the rat's ears for $.5 \mathrm{sec}$ via moist alligator clips and 500-ohm resistor in series with $S$.

\section{Procedure}

Two groups of Ss were given a $40-\mathrm{mA}$ (average current) ECS. The Ss of one group (ECS-24 h) were then returned to their home cages for a $24-\mathrm{h}$ period, while those of the other group (ECS-.09 h) were placed in waiting cages for $.09 \mathrm{~h}$. Half of the third group (control) was treated the same as the ECS-.09 h group and the remaining half, the same as the ECS-24 h group, except that a pseudo-ECS replaced ECS for these Ss. After the appropriate waiting periods, .09 or $24 \mathrm{~h}, \mathrm{ECT}$ was determined for both experimental and control groups. Each group was subdivided into four groups of 10 Ss each, and each subgroup was subjected to a different level of shock. The shock levels used were $10,12.5,15$, and $17.5 \mathrm{~mA}$ for the ECS -.09 h subgroups; 7.5 , $10,12.5$, and $15 \mathrm{~mA}$ for the control subgroups; and 5,7.5, 10, and $12.5 \mathrm{~mA}$ for the ECS-24 h subgroups. The percentage of Ss convulsing at each level was recorded; the criterion for a convulsion was the same as that in Experiment 1.

An estimate of the effective impedance to current was also obtained for each rat. This was accomplished by first plotting curves for voltage drops across a fixed resistor (500 ohms) in series with various known resistances at each of the preset milliampere levels used. The voltage drop across the 500-ohm resistor in series with $S$ during stimulation was then read from a Tektronix Type 564 storage oscilloscope and the corresponding resistance value was obtained from the preestablished curves. While this procedure ignores the relative contribution of the reactive component to the total impedance measurement, Russell et al (1949) have shown that with a 60 -cycle source frequency, the reactive component contributes less than $1 \%$ to the effective impedance of the rat under ECS stimulation.

\section{Results}

Thresholds. The percentage of Ss convulsing in each group at the various shock levels is shown in Fig. 2. The means (thresholds) and standard deviations of these functions were obtained by an ordinary least-squares solution. In general, these data support the finding of Experiment 1, that the effects of ECS on ECT are time-dependent. In the present experiment, there was a similar tendency for ECT $(9.6 \mathrm{~mA})$, determined $24 \mathrm{~h}$ after administration of the initial ECS, to be somewhat lower $(\mathrm{t}=2.20, \mathrm{df}=6$, $.025<\mathrm{p}<.05$, one-tailed) than the 13.3-mA threshold obtained when no previous shock was given, and for ECT $(15.4 \mathrm{~mA})$ to be elevated when determined $.09 \mathrm{~h}$ after a previous convulsive episode $(t=3.93, d f=6, p<.005$, one-tailed $)$.

Resistance. A 2 by 3 analysis of variance on the resistance data of the three groups at the two intermediate shock levels (10 and $12.5 \mathrm{~mA}$ ) yielded an overall significant $F(F=3.90, d f=5,54 ; p<.01)$. There was, however, no consistent relationship between the resistance measures and the percentage of $\mathrm{S}$ s convulsing at these shock levels. A Duncan range test was used for individual comparisons. At the $10-\mathrm{mA}$ level the mean resistance of the control group was somewhat lower, although not significantly, than means of both experimental groups, whereas at the 12.5-mA level the control resistance tended to be higher than the resistance of both experimental groups but differed significantly $(p<.01)$ only from that of the ECS-24-h group. At neither level did the resistance of the experimental groups differ significantly. This finding is in agreement with the contention that changes in ECT are not attributable to changes in tissue impedance (Walter \& Golla, 1940).

\section{DISCUSSION}

The elevation of ECT obtained in this study is in agreement with previous reports on threshold changes produced by ECS in both human (Kalinowsky \& Kennedy, 1943) and animal (Essig et al, 1961) Ss. Kalinowsky \& Kennedy (1943), for example, reported the necessity to increase the intensity and/or duration of snock in the course of therapy, and Essig et al (1961) reported that the ECT of the cat

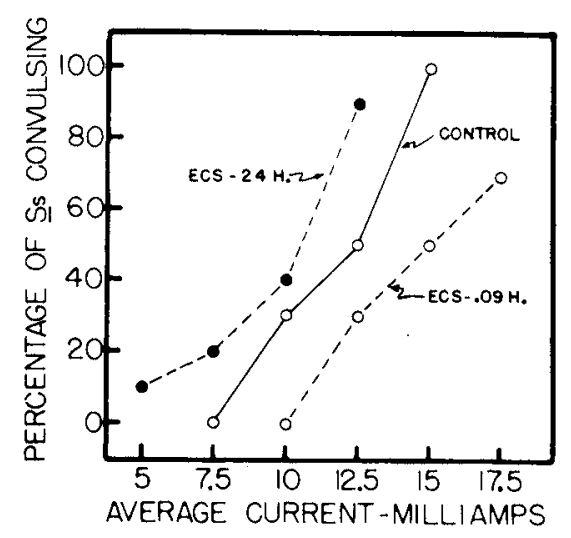

Fig. 2. The percentage of Ss convulsing as a function of shock intensity and treatment condition. The .09 and 24 indicate the ECS-ECT interval in $h$.

tended to rise with successive determinations. Similarly, Golub \& Morgan (1945) reported that repeated shocks tend to increase the ECT of the rat. This threshold-elevating effect has been taken by some investigators (e.g., Kalinowsky \& Kennedy, 1943) as evidence against the notion that a convulsive episode is facilitated by a previous convulsion. In most studies on the effects of ECS on ECT, however, the possible facilitory effect of one convulsion on another is obscured as a result of the procedure typically used in determining ECT, i.e., gradually increasing shock levels until the convulsion occurs. As mentioned previously, the consequence of this procedure is an elevation of ECT. The present experimental procedure circumvented the confounding effects of repeated shocks, and the results suggest that there are both facilitory and inhibitory effects of one convulsion on a subsequent one and that these effects are time-dependent. Inmediately and for a short period of time after an initial ECS, ECT is elevated, whereas at an ECS-ECT interval of $24 \mathrm{~h}, \mathrm{ECT}$ is slightly depressed.

Implications for Behavioral Research

The present results suggest that the joint usage of passive-avoidance training and a 24-h training-test interval may be inappropriate for investigations of the retrograde amnesic (RA) effects of ECS. A lowered ECT $24 \mathrm{~h}$ after ECS indicates a heightened excitability of the CNS (Woodbury, 1954) which may be expressed behaviorally as hyperactivity and, hence, as an augmentation of the active responses in terms of which the RA effects of ECS are evaluated. That this heightened excitability of the CNS is expressed behaviorally as an overreaction to stimuli has recently been demonstrated (Misanin \& Lewis, 1970), and it has been shown that this overreactivity tends to augment responses 
learned prior to or following ECS administration (Misanin \& Smith, 1970). These findings suggest that some consideration should be given to the selection of an optimal training-test interval in research on the RA effects of ECS, an interval that would obviate "stimulus change" as a possible factor in altered responsivity (Heistad. 1957).

The present results are also relevant to the recent finding (Kopp. Bohdanecky, \& Jarvik, 1968) that repeated ECS treatments prior to training depress the slope of the temporal gradient of RA produced by posttraining ECS. Since the slope of the RA gradient has also been shown to decrease with an increase in ECS intensity (Miller, 1968), it is possible that ECS given repeatedly to animals prior to training reduces their ECT to such a level that their posttraining ECS is equivalent to an ECS of greater intensity given to animals whose ECT has not been altered. That repeated ECS treatments would enhance the depression of ECT found in the present study is suggested by the observation that spontaneous convulsions occur in animals subjected to multiple ECS treatments (Essig, Groce, \& Williamson, 1961).

\section{REFERENCES}

CAMPBELL. B. A., \& TEGHTSOONIAN, R. Electrical and behavioral effects of different types of shock stimuli on the rat. Journal of Comparative \& Physiological Psychology, 1958. 51.185-192.

ESSIG, C. F., GROCE, I. E. \& WILLIAMSON, E. L. Reversible elevation of electroconvulsive threshold and occurrence of spontaneous convulsions upon repeated electrical stimulation of the cat brain. Experimental Veurology. 1961. 4, 37-47.

GOLLB. L. M.. \& MORGAN. C. T. Patterns of electrogenic seizures in rats: Their relation to stimulus intensity and to audiogenic seizures. Journal of Comparative \& Physiological Psychology, 1945, 38, 239-245.

HEIST AD. G. T. A bio-psychological approach to somatic treatments in psychiatry. American Journal of Psychiatry, 1957, 114, 540-545.

KALINOWSKY, L. B., \& KENNEDY, F. Observations in electric shock therapy applied to problems of epilepsy. Journal of Nenvous \& Mental Disorders, 1943, 98, 56-57.

KOPP, R., BOHDANECKY, Z.. \& JARVIK, M. $E$. Proactive effect of a single electroconvulsive shock (ECS) on one-trial learning in mice. Journal of Comparative \& Physiological Psychology, 1968, 65, 514-517.

MERITT. H. H., \& PLTNAM, T. J. A new series of anticonvulsant drugs tested by experiments on a nimals. Archives of Neurology \& Psychiatry, 1938, 39, 1003-1015.

MILLER. A. J. Variations in retrograde amnesia with parameters of electroconvulsive shock and time of testing. Journal of Comparative \& Phy siological Psychology. 1968. 66.40-47.

UISANIN. J. R.. \& LEWIS. D. F. Sensitivity and reactivity to foot shock following electroconvulsive shock stimulation. Physiology \& Behavior. 1970.5. 397-405.
MISANIN. J. R.. \& SYITH. ‥ Iः. The effect of training on ECS-induced hyperreactivity to footshock. Psychonomic Science. 1970. 20 43-45.

RLSSELL. R. W., PIERCE, J. $r_{.}$\& TOWNSEND, J. C. Characteristics of tissue impedance in the rat under conditions of electroconvulsive shock stimulation. American Journal of Physiology, 1949, 156, 317-421.

WALTER. W. G.. \& GOLLA, F. L. Electrically induced convulsions. Lancet, 1940, 238, 127. WOODBLRY, D. M. Effect of hormones on brain excitability and electrolytes. Recent Progress in Hormone Research, 1954, X, 65-107.

WOODBLRY, L. A., \& DAVENPORT, V. D. Design and use of a new electroshock seizure apparatus, and analysis of factors altering seizure threshold and pattern. Archives Internationales de Pharmacodynamie et de Therapie, 1952, XCII, 97-107.

\title{
Retention of latent inhibition*
}

\author{
SHEPARD SIEGEL \\ McMaster University, Hamilton, Ontario, Canada
}

The purpose of the experiment was to determine whether or not latent inhibition (the deleterious effect of preconditioning exposure to the CS on subsequent acquisition) is attenuated by interpolating a delay between the last session of preconditioning exposure to the CS and the first session of acquisition. Independent groups of preexposed Ss were given classical eyelid conditioning either immediately following their 550th CS-alone presentation, or $24 \mathrm{~h}$ after their 550th CS-alone presentation. Control groups had no experience with the CS prior to acquisition. Preexposed Ss were slower to acquire the CR than were control Ss, replicating previous reports of latent inhibition in the eyelid conditioning situation. Furthermore, the magnitude of latent inhibition was unaffected by the interpolation of a delay interval between preexposure and acquisition.

A number of classical conditioning studies have demonstrated that, with a variety of species, preacquisition exposure to the CS retards acquisition (see reviews by Cantor, 1969; Siegel, in press). This phenomenon has been termed "latent inhibition" (Lubow \& Moore, 1959). In contrast with findings demonstrating latent inhibition, Suboski, DiLollo, \& Gormezano (1964) have reported that preexposing rabbits to the CS does not retard subsequent nictitating membrane conditioning. It does not appear likely that this finding was due to the species used, since other investigators have subsequently reported latent inhibition with rabbit Ss (Lubow, Markman, \& Allen, 1968; Siegel, 1969a, b, in press). Lubow et al (1968) suggested that one feature of the Suboski et al (1964) investigation that may have accounted for their failure to demonstrate latent inhibition was the interpolation of a 24-h period between the last preexposure session and the first acquisition session. Suboski et al (1964) preexposed Ss to the CS during four daily sessions (70 CS presentations per day), with a $24-\mathrm{h}$ delay between the last preexposure session and

* This rescarch was supported by Grant APA-0298 from the National Research Council of Canada. the first acquisition session. It is possible that preexposure effects dissipate over time, and interpolating a 24-h interval between preexposure and acquisition would eliminate the effects of such preexposure on acquisition.

The present experiment was designed to assess the degree to which a $24-\mathrm{h}$ delay between preexposure and acquisition attenuates latent inhibition.

\section{SUBJECTS AND APPARATUS}

The Ss were 47 experimentally naive male New Zealand White rabbits, weighing $2.3 \mathrm{~kg}$. Conditioning was carried out in a sound-attenuated chamber, with $\mathrm{S}$ placed in a restraining box within the chamber. The outer eyelid response was recorded with a modification of the technique described by Gormezano (1966). Briefly, movement of $\mathrm{Ss}^{\prime}$ left outer eyelid was conducted, via a string and pulley arrangement, to the shaft of a microtorque potentiometer. Voltage changes through this potentiometer were graphically recorded and provided a measure of eyelid activity.

The US consisted of a 100-msec, 200-V ac shock, delivered to a pair of chronically implanted titanium wire electrodes, mounted approximately $1 \mathrm{~cm}$ apart and $1 \mathrm{~cm}$ below the left eye. The CS was a $500-\mathrm{msec}, 2,000-\mathrm{Hz}$ tone at $82 \mathrm{~dB}$ above 